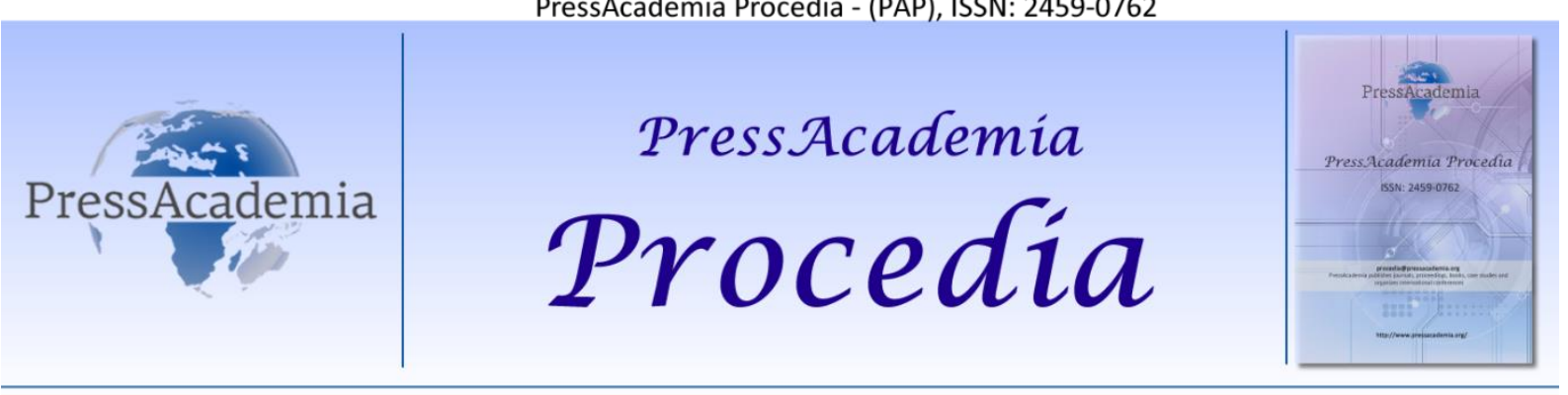

2nd World Conference on Technology, Innovation and Entrepreneurship

May 12-14, 2017, Istanbul, Turkey. Edited by Sefer Şener

\title{
EXAMINATION OF THE EXPERIENCE PHENOMENON OVER COMMERCIAL AREA EXAMPLES
}

DOI: 10.17261/Pressacademia.2017.548

PAP-WCTIE-V.4-2017(40)-p.306-312

Isil Ozcam

Mimar Sinan Fine Arts University, isil.ozcam@msgsu.edu.tr

\begin{abstract}
Nowadays, competition among firms is increasingly intensified and brands are looking for new approaches to get attention in the market. Most brands, in order to come forward in this race, organize their spaces in a recollective way in specific themes, and some adopt the concept of personalisation in design. While shop windows are becoming new focus points for communication, the virtual reality environments and augmented reality applications that are shaped by modern technologies lead to the emergence of new types of experience. Experience phenomenon which is deemed to be one of the ways to create value in today's economy is to be examined within this article through examples from commercial spaces.
\end{abstract}

Keywords: Experience, economy, retail, commercial, space.

JEL Codes: N20, N21, M10

\section{INTRODUCTION}

Nowadays, it is seen that firms are increasingly abandoning traditional marketing methods, and they are utilising experience marketing methods in order to provide their customers with more effective communication instead of merely selling them good and services. Firms that act with this point of view may include thematic designs in their commercial spaces, they may form spatial settings with eye-catching elements, and bring new interpretations to the phenomenon of experience by utilising technological opportunities. Scientific and technological developments increase the competition among firms, and the consumer society we are in brings about differentiation, catchiness and transformability. The most striking thing in this process of change is that, with the increasing amount of competition, establishments are urged to produce goods and services that will surpass the demands and needs of their customers, and create experiences that will direct emotional searches along with this (Güzel and Papatya 2012). It is observed that the concept of 'theatricality' is a concept that is increasingly becoming important in today's economy, where concepts like 'ingenuity', 'brand identity' and 'difference' are popular.

\section{THE RELATIONSHIP BETWEEN THE CONCEPT OF EXPERIENCE AND MARKETING}

The concept of experience, which is defined by the Turkish Language Society as "the entirety of information a person gathers through a specific time or in their whole life, knowledge," is the fourth type of economic offerings in addition to commodities, good and services according to Pine and Gilmore. Accordingly, goods and services are not sufficient anymore and people are looking for the original and the catchy (Pine and Gilmore 1999). According to some studies, it was seen that the experience of buying created more satisfaction and happiness in people than buying something. Moreover, technological opportunities that allow new experiences are rapidly developing today, and the increasingly intensified competition promotes efforts towards product differentiation. Increased levels of prosperity determine the preferences and priorities of individuals, and thus, many brands today add experience onto their products and services and try to make their offerings different. It is increasingly hard to compete in the global economy of our time (Carù \& Cova, 2003, 2007a). Firms that want to come forward in this level of product and brand diversity try to create recollective customer experiences by using different stimulants and contents in the commercial environment (Yuan and $\mathrm{Wu}, 2008)$. The dynamics in question are constructed with the effects of several factors such as visual stimulants, colours and sounds, and these dynamics may 
reveal people's emotions and feelings (Thusy and Morris, 2004). One example to the issue is that classical music played in shops leads customers to perceive the goods sold and the service provided to have more quality and prestige (Soars, 2003, p.631). Considering that many purchasing decisions are taken at the store and the point of shopping, it is possible to say that in-shop factors are more effective than advertisements and other marketing activities (Baker et al., 1994, p.328); and experiences constitute the basis of economic activities among other economic offerings of this era.

According to Holt, today's consumers prefer brands that inspire them, they stimulate and enrich their imagination, and that they are able to experience (Holt, 2002). Thematic spaces may be interpreted in this sense, for example, Disneyland, which is an example of a thematic park was first opened in California in 1955. Walt Disney, who started from the idea of 'a cartoon that will embrace the viewers', aimed to create an experience in which parents are able to have fun time with their children. Stores such as Build-A-Bear, Jordan's Furniture and Niketown try to attract customers by various events and instore elements. Such experiences focused on entertainment are also known today as 'entertailing' or 'shoppertainment'.

Figure 1: Build a Bear Workshop Retail Space, Akasya Shopping Center, Istanbul
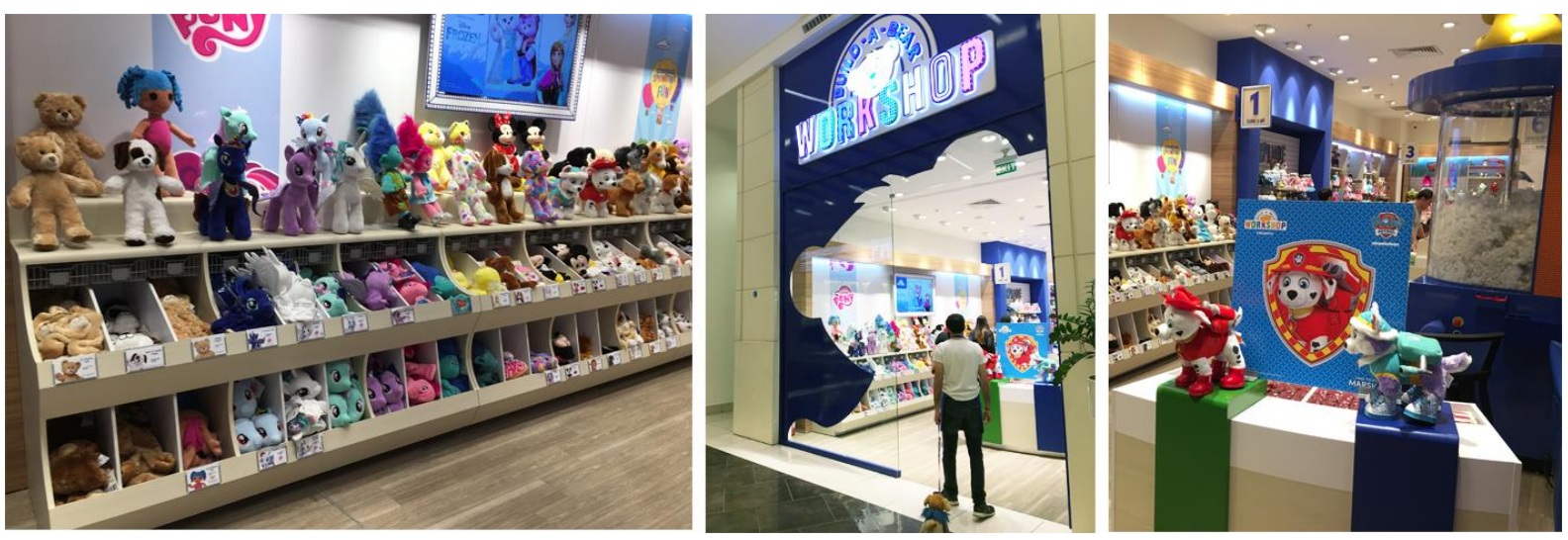

The interest on the experimental types of consumption started with the emphasis of Holbrook and Hirchman on the symbolic, hedonic and aesthetic properties of consumption in the beginning of 1980s (Holbrook 1982). These authors discussed radical changes in consumption behaviours and emphasized the effects of factors of fantasy, emotion and entertainment on consumption habits. Other authors also published articles in the following years about the relationship between the experience of consumption and emotions (Peterson, 1986; Havlena \& Holbrook, 1986). Concepts such as the 'communication value of the brand', 'marketing studies that target emotions' and 'experience of shopping that provides a lifestyle' which became prominent as the ways of consumption and consumer needs started to change in 1990s, have started to become the approaches utilised by firms due to the effects of advanced technology (Dell'era, 2010). Therefore, many authors have published articles in the last 15 years on experimental marketing and experience economics (Schmitt and Simonson, 1997; Pine and Gilmore, 1998, 1999; Schmitt, 1999a, b, c; Addis and Holbrook, 2001; Berthon et al., 2003; Fulberg, 2003; Joy and Sherry, 2003; Arvidsson, 2005). The concept of experience economy was coined by Pine and Gilmore in 1999 in the study titled 'the Experience Economy'. In the study, the authors stated that institutions pay importance on binding their customers by creating experiences and emphasized the concept of theatricality. According to this, 'goods and services are no longer sufficient; it is necessary to display experiences to create value'. They described interesting theatrical experiences with the items 'keeping the attention, changing the context, creating a feeling of appreciation, changing the state a person is in, achieving presence, and providing a feeling of refinement/relaxation' (Pine \& Gilmore 1999). Schmitt, in the article he wrote with the title 'Experimental Marketing' in 1999, stated that traditional marketing methods are now in the past, and a new economic model based on sensing, feeling, thinking, playing and establishing relationships emerged, and called it experimental marketing (Schmitt 1999c). Examples that may be interpreted in terms of experience economics include thematic spaces, Las Vegas, Disneyland, HIP Hotels (Highly Individual Places), websites, virtual reality applications (Dell'era 2010). As also emphasized by Floor, shopping today is not only related to selling goods, but customers also have fun time and relax while buying products (Floor 2007). Morgan (2008), while analysing current tendencies, stated that people shop with purposes of entertainment today, while shopping surpassed being an activity of meeting needs and became a pastime activity. Increased competition among firms lead to the in-store atmosphere to come to a state to serve brand identity and experience provided to the customer. Thus, commercial space designs are increasingly becoming places that include theatrical/catchy elements.

\section{TYPES OF EXPERIENCE}

Nowadays, in addition to goods and services, firms also try to provide experienced enriched with senses in their spaces. Experience is formed on an emotional, physical, intellectual and even spiritual level. If goods are tangible and services are 
intangible, experience is catchy. Pine and Gilmore (2011) investigated the factor of experience in a commercial space under four main titles. 'Education, entertainment, escape and aesthetic pleasure', which are named as the four areas of experience, are actually mostly intertwined and interrelated elements. The experiences people see as 'entertainment' are usually experiences they passively take in as in reading a book, watching a show or listening to music. In the experience of 'education', the viewer intakes the events presented, and the thing that is provided is information/educational content. Stores publishing their history as books may be provided as an example of an educational activity that requires active mental and/or physical participation. 'Escape' comprises more of the dimension of entanglement, and the participant is active in the process. Thematic parks, computer games, virtual reality and augmented reality applications may be an example of this. In aesthetical experiences, individuals enter an activity or an environment, but they usually have no effect on this environment. Visiting a gallery or sitting before a view, placement of a mountain inside a store, covering the space in a certain style or an installation established in the space may be given as examples of this. While the purpose is learning in educational experience, going and doing in escape experience, sensing in entertainment experience, the purpose of participants in aesthetical experience in just being there. For example, Niketown in Chicago was designed as a place that includes exhibitions of the histories of old show models, Sports Illustrated issues where athletes wearing Nike are featured on the cover, half a basketball court and activities such as mobile cinemas in which video clips of famous athletes are shown, which provides the experience of education along with entertainment and aesthetical experience. This place was constructed as a theatre where consumers would participate as viewers who contribute into the production process (Pine and Gilmore, 2011).

\section{EXPERIENCE-ORIENTED FORMATION OF COMMERCIAL SPACES}

Shaping of commercial spaces as experience-oriented may take place in educational, entertainment-based, escape-based and aesthetical dimensions as mentioned above, and spaces may be organized in scope of themes based on these experiences. Themes are intangible concepts that lead the visitors to reach a comprehensive story line by changing the sense of reality of them and with the help of design elements supporting each other. Yurttas defined 'theme' as the load of perception, story, message and emotion that is felt in strongly or weakly in a selected subject and wanted to be transmitted to the viewer. The influence and impression felt by a user regarding a space may be defined as the theme of that space (Yurttaş, 2010). Themes may be very diverse, and examples include certain historical periods, artistic movements, fields of sports, lifestyles, geographical features, cultures, concepts, tales, colours, materials, and technology usage. In addition to themes, experiences supported by activities in spaces also play an important role in marketing strategies of brands nowadays. One example of these activities is the Build-A-Bear Workshop store which has a branch in the Akasya Mall. There are various stations in this store, where children can design their own teddy bears. Children, who shape their bears with the materials they choose in these stations, complete their designs by stuffing the toys. Such an experience not only establishes a relationship between the firm and its customer, it also forms a connection between the guest and the product. The method of adaptation of the product to the customer allows participants to customise the products based on their needs. Today, several famous companies have adopted this method to gain advantages over their competitors in the market. Lego is another form that designs sale areas as a playing room for children and allows in-store interactions. Children who are allowed to play with Lego blocks on centre modules can form their characters using these piece, and therefore customise their toys. Large-scale Lego sculptures in the space not only show what can be done with the products of the brand as educational object, but they also contribute to the aesthetics of the space as symbolic products.

Figure 2: Images From Lego Stores
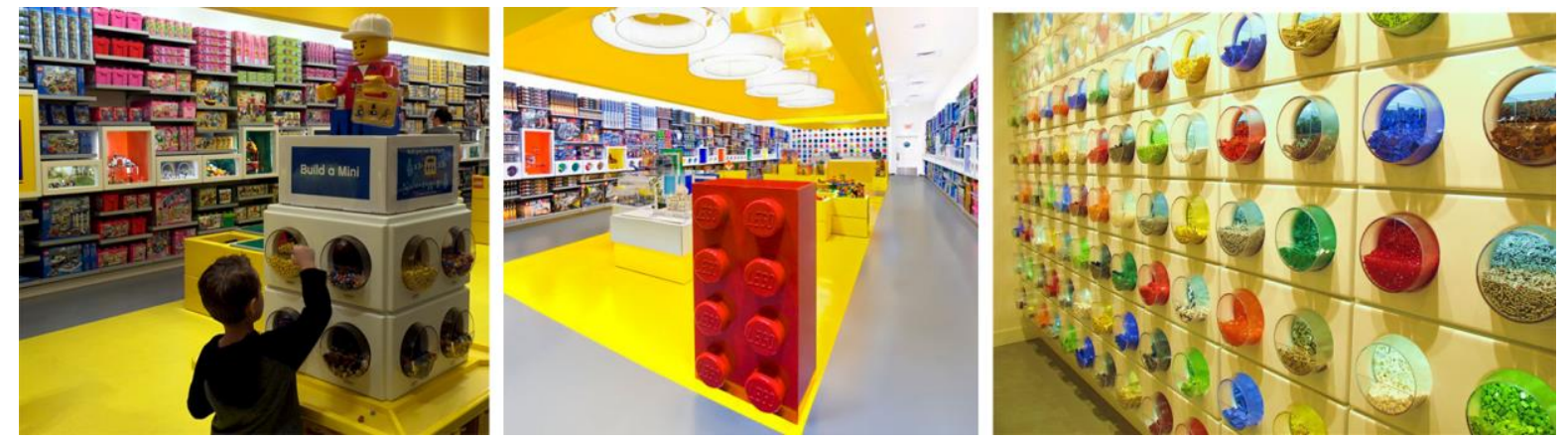

Affectualisation of products is one of the most direct ways of making the products heuristic. This is possible by adding elements that will lead the customer to start a sensory interaction with the product. While usage of examples such as toys, Lego blocks, candies lead to a direct sensory experience, some firms achieve appreciation by using symbolic products in their spaces. Producing objects in exaggerated dimensions is a frequently used method in this matter. Production of the world's largest Duct Tape by the firm Duct Tape and exhibition of it in a store lead the customer of the firm to look at this 
symbolic object and be informed about it, and the image of the brand in the mind of the consumer to be established. A large chair built by the firm 'Sandalyeci' that appears in public in recent years is another example. Sometimes, it is seen that symbolic object that represent the brand identity are used in stores in aesthetical and functional dimensions. The Beetle car placed in the middle of the store by the brand PRO 010, which appeals to young people as a trainer shoes brand, emphasises a certain lifestyle.

Figure 3: PRO 010 Retail Store, Amsterdam
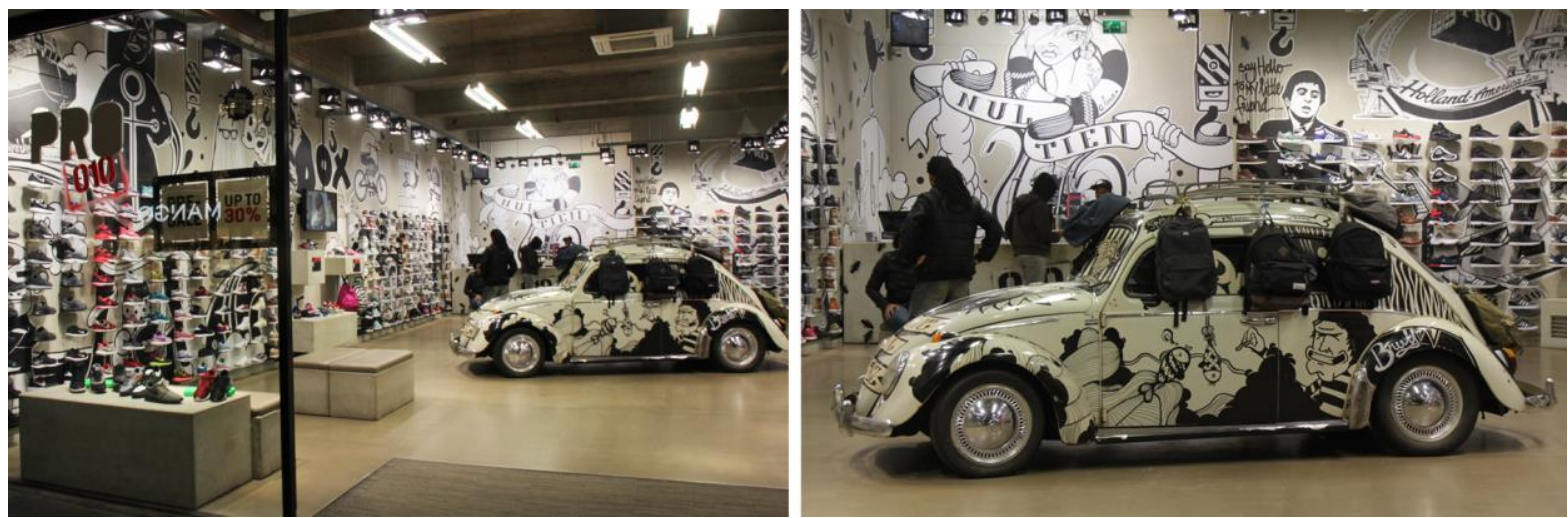

Experience-oriented thematic approaches are also frequently seen in common usage area designs of shopping malls. Forum Shops that were designed as ancient roman markets may be given as examples of spaces that provide aesthetical experience where a certain time period or a concept is depicted. In this shopping mall opened in 1992 in Las Vegas, the architecture and all peripheral elements are supportive of the theme in question. Another example of thematic areas in shopping malls is the istinye Market located in the İstanbul İstinyepark shopping mall. The walls that resemble building facades in the space and counters selling fruits and vegetables represent the concept of district bazaars. With the barrisol material used in the ceiling of the area, it was aimed to create an atmosphere like walking in open space.

Figure 4: İstinyepark Bazaar
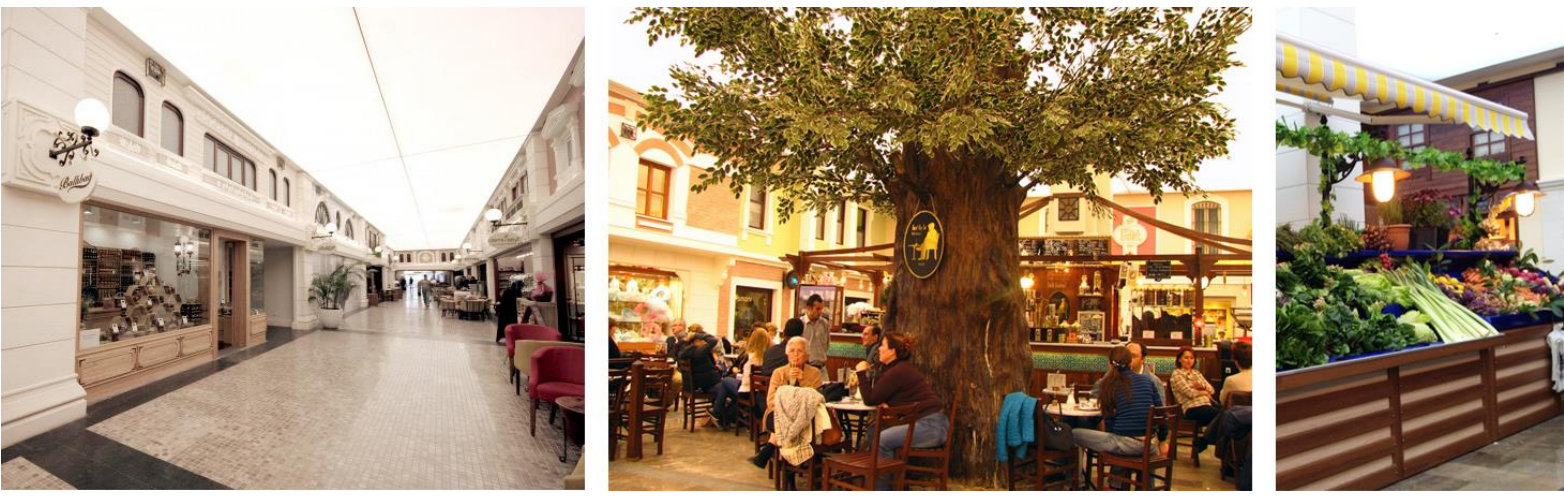

Retailers that sell outdoor sports materials such as Bass Pro Shops Outdoor World, Recreational Equipment Inc., Cabela's include elements that are for sports activities or hunting in their store designs and try to create a theme of 'adventure' in their space. Bass Pro Shops designed their store as a forest, and REI built a mountain of 15-metre height for people to test their climbing materials. In the Cabela's store located in Minnesota, there is a 10-metre-high mountain with an artificial waterfall and wild animals that were taxidermized after shooting. Climbing walls that provide an experience of entertainment for both participants and watchers have recently been see frequently in shopping malls, university campuses and public areas. 
Figure 5: Photos from Cabela's and Bass Pro Shops stores
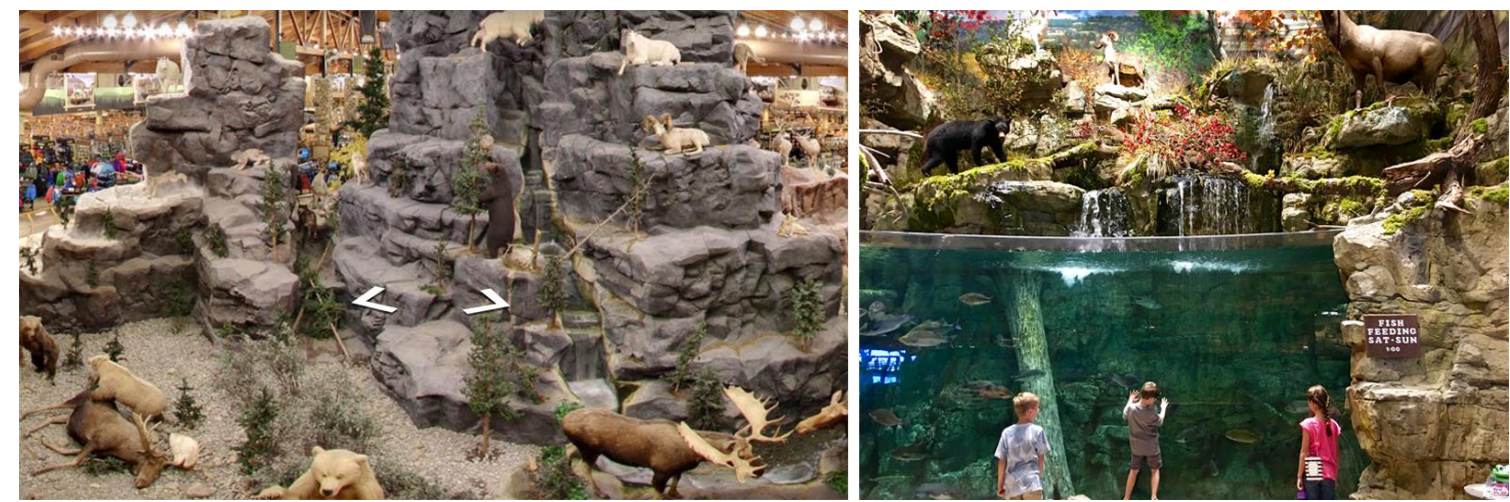

Another dimension of the concept of experience in commercial spaces is the dynamics created by store window designs. After production of large glass panels in the beginning of 1840s, especially multi-story stores became able to improve their window design and make some organizations (Bayraktar, 2011). The Selfridges store opened in London in 1909 became a pioneer by leaving the lights on at night for their windows that they designed theatrically. This firm is one of the examples of firms that use their windows most effectively. Activities organized by Selfridge are considered to be one of the first steps taken in terms of experience in the past. The firm, which loaded the plane that was landed onto a field by Louis Bleriot who crossed the English Channel for the first time at night, brought the plane to the store next day at 10:00, and this resulted in 50,000 people lining up in front of the store (Morgan, 2008, p.13). Digital screens that started appearing with the pioneering of Gucci and Prada in 1990s carried the concept of window design and experience to another level. Usage of new communication theories and technologies makes the window no longer a passive show element, but it makes new presentation approaches that see the window as an active tool for emotional connection a new interface for communication (Erda, 2010, p.30). Some brands include installation works in their store in order to create a genuine image, and work with various artists and designers for this. These structures designed towards creation of an aesthetical experience in the space may contribute to the space functionally, or they may only have visual purposes. The temporary installation made for the brand Aesop by the Cheungvogl Architecture Firm in Hong Kong, used modules to display care products. A total of eight hundred resin boxes that represented flying lanterns were placed on steel rods in different heights. The installation was later transported to the first floor of the Hong Kong I.T Hysan shopping mall. The exhibition design was carried out by the creative director of Aesop, Hiroko Shiratori, in the firm's pop-up store opened in Tokyo Midtown Galleria. Stacked chairs were used in the installation, and the resulting surfaces were used to place products. Considering the works of firms such as Aesop that include similar installations in their spaces, it is seen that usage of installations in commercial spaces may be an approach of marketing for firms.

Figure 6: Hong Kong Aesop Retail Store and Tokyo Aesop Pop-up Store
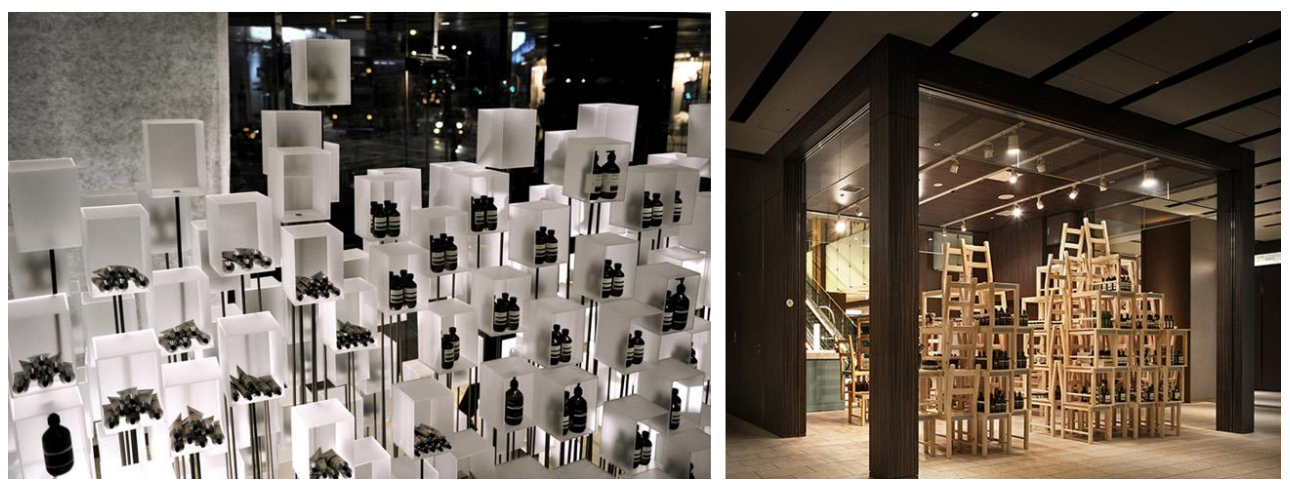

In addition to the technological advancements of today, the factor of experience in commercial spaces also vary, and brands are increasingly interested in virtual reality / augmented reality applications. While interactive spaces contribute to customers playing an active role in the store, they allow achieving the relationship with products to different extents. Nokia's store in London is a digital installation that is experienced by customer participation. It is also an indicator that institutions have started to pay importance to experimental interactive designs in the process of building brands. Translucent panels and LCD screens in the space allow customers to change the in-store appearance by using the function 
of messaging. This way, an organic relationship takes place between the customer and the product, and the concept of experience is customised due to the effects of this interaction in the space.

Figure 7: Nokia Store, London
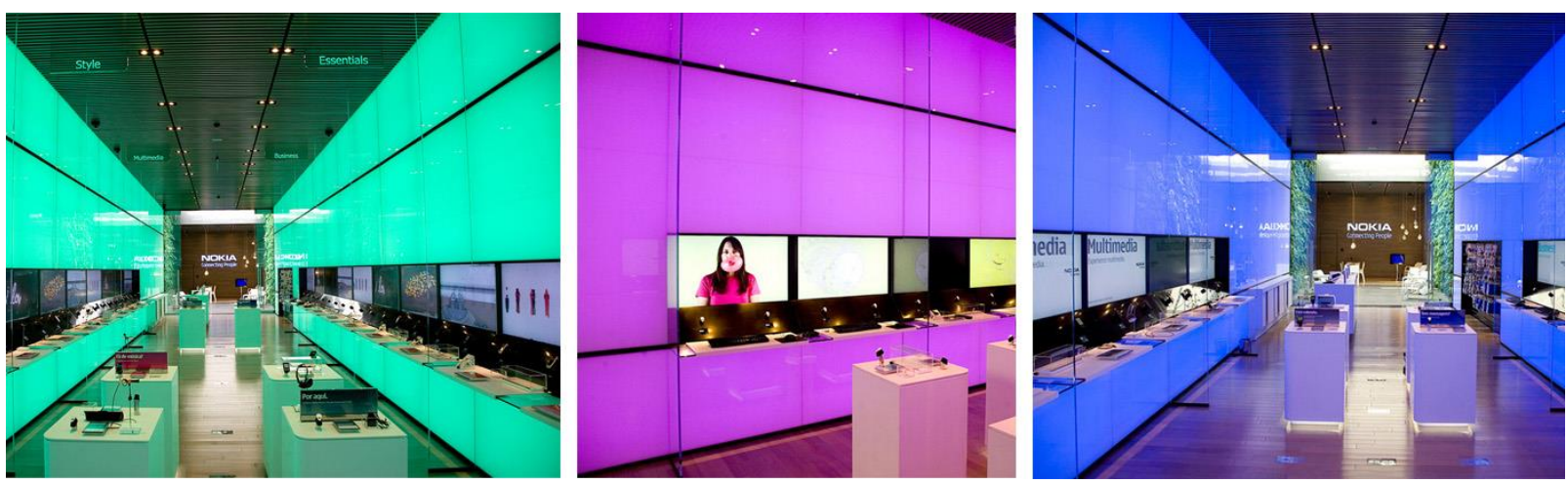

All these examples show that, in the market economy of our time, brands see their commercial spaces as stages that allow different types of experiences in order to gain advantages over their competitors. Firms no longer provide goods and services only, but they try to also provide experiences enriched by emotions that are evoked in customers, and they utilise different methods for this. The concept of experience in commercial spaces is supported by experiential approaches such as thematic designs, usage of symbolic products in the space, marketing strategies that allow customisation in the product scale, activities organized in the store, dynamics created in the space by installation elements, and interactions among individuals at and with the space based on usage of technology.

\section{CONCLUSION}

More firms are trying to customise their presentations by entangling their current goods and surfaces with experience every day, and they include experiential elements in the space of sales. Considering that customers look for psychological satisfaction in addition so simple consumption in the process of shopping, the reason for this approach may be understood. The examples show that the concept of experience in the commercial space is supported by design decisions. In the increasingly intensified competition environment, the needs of brands like 'being original, uniqueness, change, symbolic value' are satisfied by marketing strategies for users who want personalised presentations, catchy symbolic products and installation works in the space, dynamics created with the virtual world, and interactive spaces. Technology that allows partially different experiences, advancement in this area, and increased levels of prosperity are factors that play a role in the increase in attempts of this nature. The new criterion of today is 'practicability', and firms that are aware of this are increasingly turning towards including experimental approaches in design processes with the purpose of being different.

\section{REFERENCES}

Addis, M. and Holbrook, M. B. 2001, “On the Conceptual Link Between Mass Customization and Experiential Consumption: An Explosion of Subjectivity", Journal of Consumer Behaviour, 1(1), pp. 50-66.

Arvidsson, A., 2005, “Brands: a critical perspective, Journal of Consumer Culture”, 5(2), pp. 235-258.

Bayraktar, A., 2011, “Görsel Mağazacılıkta Vitrinlerin Önemi”, Beta Publications, 2011.

Baker, J., Grewal, D., Parasuraman, A. ,1994, 'The Influence of Store Environment on Quality Interfaces and Store Image', Journal of Academy of Marketing Science, 22(4), pp. 328-339.

Berthon, P., Holbrook, M. B. and Hulbert, J. M., 2003, “Understanding and Managing The Brand Space, Sloan Management Review, 44(2), pp. 49-54.

Carù, A., \& Cova, B., 2003, "Revisiting Consumption Experience: A More Humble But Complete View of the Concept. Marketing Theory", 3(2), pp. 259-278.

Carù, A., \& Cova, B., 2007a, “Consuming Experience. London”, UK: Routledge.

Dell 'era, C., 2010, “Art for Business: Creating Competitive Advantage through Cultural Projects", Industry and Innovation Journal, pp. 7189.

Erda, S., 2010, “Tüketim İletişiminin Bir Arayüzü Olarak Vitrin”, Vitrin Magazine, 08/09 2010, pp.30-31.

Floor, K., 2007, "Branding a Store: How to Build Successful Retail Brands in a Changing Market Place”, Kogan page, $192-204$. 
Fulberg, P., 2003, "Using Sonic Branding in the Retail Environment-An Easy and Effective Way to Create Consumer Brand Loyalty While Enhancing the In-Store Experience", Journal of Consumer Behaviour, 3(2), pp. 193-198.

Güzel, f., Ö., Papatya, N., 2012, “Duygusal Arayışların Pazarlamayla Dansı: Deneyim Pazarlaması Kavramsal Bir Analiz”, İ̧̧letme Araştırmaları Dergisi, 4/4, pp.109-125.

Havlena, W. J. and Holbrook, M. B., 1986, "The Varieties of Consumption Experience Comparing Two Typologies of Emotion In Consumer Behavior", Journal of Consumer Research, 13(3), pp. 394-404.

Holbrook, M. B.; Hirschman, E. C., 1982, "The Experiential Aspects of Consumption: Consumer Fantasies, Feelings and Fun”, Journal of Consumer Research, 9, pp. 132-140.

Holt, D. B., 2002, "Why Do Brands Cause Trouble? A Dialectical Theory of Consumer Culture and Branding”, Journal of Consumer Research, 29, pp. 70-90.

Joy, A.; Sherry, J. F., 2003, "Speaking of Art As Embodied Imagination: A Multisensory Approach To Understanding Aesthetic Experience", Journal of Consumer Research, 30, pp. 259-282.

Morgan, T., 2008, "Visual Merchandising, Window and Display for Retail”, Laurence King, London.

Peterson, R. A., Wayne, D. H., Wilson, W. R., 1986, "The Role of Affect in Consumer Behaviour: Emerging Theories and Applications", Lexington, MA: D.C. Heath.

Pine, B. J.; Gilmore, J. H., 1998, "Welcome To The Experience Economy", Harvard Business Review, July-August, pp. 97-105.

Pine, B. J.; Gilmore, J. H., 1999, "The Experience Economy-Work is Theatre \& Every Business a Stage”, Boston, MA: Harvard Business School Press.

Pine, B.,J., Gilmore J., H., 2011, “Deneyim Ekonomisi”, Optimist Yayınları, İstanbul.

Schmitt, B.; Simonson, A., 1997, “Marketing Aesthetics-The Strategic Management of Brands, Identity, and Image”, New York: The Free Press.

Schmitt, B., 1999a, "Experiential Marketing", Journal of Marketing Management, 15, pp. 53-67.

Schmitt, B., 1999b, “Experiential Marketing: A New Framework for Design and Communications”, Design Management Journal, 10(2), pp. 10-16.

Schmitt, B., 1999c, "Experiential Marketing-How to Get Customers to Sense, Feel, Think, Act and Relate", New York: The Free Press.

Soars, Brenda, 2003. "What Every Retailer Should Know About the Way Into the Shopper's Head", International Journal of Retail \& Distribution Management, 31(12), pp.628-637.

Thusy, A., Morris, L., 2004, “From Crm To Customer Experience: A New Realm For Innovation”, Business Digest, Paris.

Yuan, Y., Chihkang, E., Wu, K., 2008, "Relatıonshıps Among Experıentıal Marketıng, Experıentıal Value, And Customer Satısfactıon”, Journal Of Hospitality \& Tourism Research, vol. 20, 1-24.

Yurttaş, N. B., 2010, “iç̧ Mekan Tasarımında 'Tema' Kavramı ve 'Tematik Mekan' Olgusunun Örnekler Üzerinden Analizi, Mimar Sinan Fine Arts University, Graduate Thesis, Graduate Shool of Natural and Applied Sciences. 